\title{
La creación entera gime y sufre dolores de parto. Reflexiones alrededor de Romanos 8,22s
}

\section{Resumen}

"Sabemos que el hombre blanco no comprende nuestra manera de ser. Le da lo mismo un pedazo de tierra que el otro porque él es un extraño que llega en la noche a sacar de la tierra lo que necesita. La tierra no es su hermano sino su enemigo. Cuando la ha conquistado la abandona y sigue su camino. Deja detrás de él las sepulturas de sus padres sin que le importe. Despoja de la tierra a sus hijos sin que le importe. Olvida la sepultura de su padre y los derechos de sus hijos. Trata a su madre, la Tierra, y a su hermano, el Cielo, como si fuesen cosas que se pueden comprar, saquear y vender, como si fuesen corderos y cuentas de vidrio. Su insaciable apetito devorará la tierra y dejará tras sí sólo un desierto."

Seattle

Aunque en "LAUDATO SI" el Papa Francisco define el mundo como "La casa común", la mayoría de la gente se comporta como miopes. No ve más allá de lo cotidiano. Aunque a través de los medios le llegan noticias de todo el mundo, no le afecta.

¿Seremos capaces de convertirnos para salvar nuestra casa?

Palabras clave: Creación. Romanos. Planeta. Tierra. Laudato Si

\begin{abstract}
"We know that the white man does not understand our way of being. One piece of land doesn't matter more to him than another, because he is a stranger who comes in the night to take from the land what he needs. The Earth is not his brother but his enemy. When he has conquered it, he abandons it and continues on his way. He leaves behind him the graves of his parents without regard. He deprives the land from his children without regard. He forgets the grave of his father and the rights of his children. He treats his mother, the Earth, and his brother, the sky, as if they were things that can bought, plundered and sold, as if they were sheep and glass beads. His insatiable appetite will devour the Earth and leave behind only a desert."

Seattle

Although in "LAUDATIO SI" Pope Francisco defines the world as "The Common house", most of people's behavior is short-sighted. They do not
\end{abstract}


see beyond the horizon. Although they get news from the media from all over the world, it does not affect them. Will we be able to change ourselves to save our House?

Keywords: Creation. Romans. Planet. Earth. Laudato Si

Después de dos mil años la madre tierra ya no sufre dolores del parto sino de agonía.

¿Por causa de quién? Sin meterme en las discusiones sobre las causas antropógenas del deterioro del planeta, les dejo algunas preguntas:

¿Alguien puede certificar que la temperatura a nivel mundial está bajando?

- ¿Que el porcentaje del CO 2 en la atmósfera está bajando?

- ¿Que el porcentaje del metano en la atmósfera está bajando?

- ¿Que los permafrost de Siberia y Groenlandia están en status quo?

- ¿Que el hielo de la antártica está creciendo?

- ¿Que los glaciales están creciendo?

- ¿Que las montañas acumulan más nieve que antes?

- ¿Que el nivel del mar está bajando?

- ¿Que las islas de Oceanía siguen creciendo?

- ¿Que la selva y bosques están creciendo?

- ¿Que la tala indiscriminada no existe?

- ¿Que la desertificación es puro cuento?

- ¿Que el agua del mar aumenta el PH?

- ¿Que el agua de los ríos y lagos no está contaminada?

- ¿Que la extracción del petróleo y minerales no perjudica la salud de los pueblos?

- ¿Qué las especies de flora y fauna están aumentando y protegidas?

- ¿Que todo eso corresponde a un proceso natural y no tiene nada que ver con la injerencia humana?

- ¿Que la brecha entre la gente rica y pobre está disminuyendo?

- ¿Qué la brecha entre países ricos y pobres está disminuyendo?

- ¿Que la ecología no es una preocupación seria por nosotros?

Para los ateos vamos inexorablemente al suicidio colectivo. Pero, ¿qué les importa? Total la muerte significa el final de esta vida, y después nada!

Para nosotros, los creyentes "gemimos en nuestro interior suspirando que Dios nos haga sus hijos y libera nuestro cuerpo." (Rm.8, 23), por lo menos según las palabras de San Pablo.

Pero para nosotros, los creyentes, que rezamos en cada misa: ¡"Esperamos la segunda y gloriosa venida de Nuestro Señor Jesucristo"! ¿No 
significa más que una fórmula litúrgica rezado de boca para afuera?

Y la invocación "Maranatha!" ¿Nos dice algo?

Antes de seguir leyendo tenemos que aceptar que el sentido ecológico era desconocido por la mayoría de nuestros antepasados.

Únicamente el mito de Génesis 2 cuenta de la armonía entre Adán y los animales. Pero la luna de miel duró poco, pues al partir del diluvio los animales tuvieron miedo al hombre (Gn.9,2). Y no era para menos, pues a partir de aquel entonces también los animales le servían para alimentarse (Gn.9,3).

\section{1. ¡Chau dulce armonía!}

Mientras tanto heredamos el castigo de la expulsión del paraíso. Recién los textos apocalípticos hablan de vuelta de la restauración de la armonía perdida, la utopía hecha realidad, tal como dicen Ezequiel 47,7-12

"Cuando regreso al torrente, veo que hay en la orilla muchos árboles, a ambos lados del torrente. ${ }^{8} \mathrm{Me}$ dijo: "Esa agua corre hacia la región este, desciende hacia la Arabá y desemboca en el mar para que sus aguas queden sanas. ${ }^{9}$ Todo ser viviente, todo lo que se mueva por donde pase el torrente se llenará de vida; la pesca será allí muy abundante. Bastará con que lleguen sus aguas para que haya salud y vida por donde ellas pasen.

${ }^{10}$ Los pescadores se instalarán en sus orillas desde En-Guedi hasta En-Elayim: alli echarán sus redes. Los pescados serán muy numerosos, de las mismas especies que hay en el Gran Mar. ${ }^{11}$ Los pantanos y lagunas, en cambio, serán insalubres; quedarán como salinas. ${ }^{12}$ En las márgenes del torrente, desde principio a fin, crecerán toda clase de árboles frutales; su follaje no se secará, tendrán frutas en cualquier estación: Producirán todos los meses gracias a esa agua que viene del santuario. La gente se alimentará con sus frutas y sus hojas les servirán de remedio.

\section{y Apocalipsis 21, 1-7}

"Después vi un cielo nuevo y una tierra nueva, pues el primer cielo y la primera tierra habian desaparecido y el mar no existe ya. ${ }^{2} Y$ vi a la Ciudad Santa, la nueva Jerusalén, que bajaba del cielo, de junto a Dios, engalanada como una novia que se adorna para recibir a su esposo. ${ }^{3} Y$ oi una voz que clamaba desde el trono: "Esta es la morada de Dios con los hombres; él habitará en medio de ellos; ellos serán su gente y él será Dios-con-ellos; 4 él enjugará las lágrimas de sus ojos. Ya no habrá muerte ni lamento, ni llanto ni pena, pues todo lo anterior ha pasado."

${ }^{5} Y$ el que estaba sentado en el trono dijo: "Ahora todo lo hago nuevo". Luego me dijo: "Escribe, que estas palabras son ciertas y verdaderas." ${ }^{6} Y$ añadió: "Ya está hecho. Yo soy el Alfa y la Omega, el Principio y el Fin. Al que tenga sed yo le daré de beber gratuitamente del manantial del agua de la vida. ${ }^{7}$ Esa será la herencia del vencedor: yo seré Dios para él y él será hijo para mí. 
${ }^{8}$ Pero para los cobardes, los renegados, los corrompidos, los asesinos, los impuros, los hechiceros, los idólatras, en una palabra, para todos los falsos, su lugar y su parte es el lago que arde con fuego de azufre, que es la segunda muerte."

\section{El "homo sapiens", en su afán de creerse igual a Dios ¿será capaz de destruir al planeta azul?}

A causa del efecto invernadero a nivel global, desde 1970 hasta ahora, la temperatura aumentó 0.87 grados Celsius ${ }^{1}$.

Nuestro profesor de geografía en los años sesenta elogiaba este fenómeno "natural", pues ahorraría mucha energía a la humanidad. Después de cincuenta y cinco años sabemos que ese fenómeno no es nada natural, sino causado principalmente por el mismo hombre a raíz del exceso de emisión de $\mathrm{CO} 2$. A pesar de este descubrimiento, el efecto fue interpretado positivamente, pues duplicando el porcentaje de $\mathrm{CO}_{2}$ en los invernáculos de 0,01 a $0,02 \%$, las verduras se desarrollan dos veces más rápido.

"La subida del océano tarda más en reaccionar a los cambios en CO2, pero la NASA dice que subió $8,6 \mathrm{~cm}$ desde $1994^{2}$. y $20 \mathrm{~cm}$ en los últimos 100 años

El problema con esto es que este proceso tiene mucha inercia $y$, si bien tarda mucho en arrancar, después dicen que va a ser casi imposible frenarlo. Por lo que entiendo, el CO2 ahora llegó $0.0405 \%$ (2017) y, si bien con un 0,02\% las plantas andan muy bien, un 0,06\% ya alcanza para elevar mucho la temperatura del mundo y destruir el medio ambiente. Así que no se llegaría a aprovechar los beneficios para las plantas de tener un CO2 más alto porque el desastre ya estaría hecho mucho antes"'.

Pero en aquel entonces no se notaba el lado negativo de la moneda: el deshielo constante de la Antártica y de la Ártica. Según los cálculos, se estima un aumento del nivel de los océanos hasta el fin del siglo a $60 \mathrm{~cm}$ y al fin del milenio hasta 60 metro! (sic).

Nos acercamos a un nuevo diluvio - pero según nuestra mentalidad: “QQué me importa, después de mí, que venga el diluvio!"”

Los científicos saben del desastre que está por venir, pero los políticos se cuidan de divulgar ese peligro, para "no alarmar al pueblo". Recién a partir de la conferencia sobre el clima en Paris 2015 las grandes naciones se comprometieron a bajar el nivel del CO2. Pero sigue vigente el dicho Entre el dicho y el hecho, hay un largo trecho!

Existe otra amenaza de que casi nadie menciona. El cambio del peso desde los polos hacia el ecuador, provocará un desequilibrio tal, que cambiará el lugar de los polos. El Tsunami solamente es el principio de

\footnotetext{
${ }^{1}$ https: / / climate.nasa.gov/ vital-signs / global-temperature/ última consulta 23/8/2019

${ }^{2}$ http: / / climate.nasa.gov/vital-signs/ sea-level/ última consulta 23/08/2019

${ }^{3}$ datos aportados por el Ingeniero Roberto L. Estevez

${ }^{4} \mathrm{Cfr}$. "El diluvio que viene," comedia de E. Discépolo.
} 
los efectos negativos que nos amenaza ${ }^{5}$. Al fin del milenio un grupo de científicos rusos descubrió que el polo norte se había corrido. En el lugar geográfico encontraron agua dulce en lugar de hielo.

\section{El planeta tierra, nuestra casa común, corre peligro a causa del homo no tan - sapiens.}

"Sabemos que el hombre blanco no comprende nuestra manera de ser. Le da lo mismo un pedazo de tierra que el otro porque él es un extraño que llega en la noche a sacar de la tierra lo que necesita. La tierra no es su hermano sino su enemigo. Cuando la ha conquistado la abandona y sigue su camino."6

Platón, en "Diálogos" ya se quejaba: "Las montañas estaban cubiertas en un tiempo no lejano de árboles gigantes, que se cortaban para enormes construcciones." 7

Las grandes flotas de los macedonios, persas y romanos fueron construidos de madera de los árboles de los bosques alrededor del mediterráneo para satisfacer a los juegos mortales de los reyes de turno. Seguía luego la desforestación para la construcción de barcos para la conquista del Nuevo Mundo.

Salomón fue uno más dentro de la cadena de depredadores del inmenso bosque del Líbano, donde hoy solamente quedaron dos "Santuarios" de algunos ejemplares milenarios. En lugar de reforestar venden los plantines de cedros a los turistas!

En la Argentina desde el principio de 1900 se deforesta por año 1 millón de selva. Solamente en la provincia de Misiones, Argentina, se talan mil hectáreas por mes (año 2005); y en la provincia de Salta pasa lo mismo, encima para sembrar soja.

Paraguay perdió $90 \%$ de la selva usando la tierra para siembra de soja y ganadería, mientras los paraguayos emigran a las villas miserias de Buenos Aires

Durante el sínodo de la diócesis de Iguazú (Misiones/Argentina) en el año 1998, los caciques guaraníes pidieron a los cristianos solamente una cosa: "Respétenos y ayúdenos a que los blancos no destruyen la selva, pues es nuestro ámbito de vida."

Argentina perdió 22\% de sus bosques, (unas 7,6 millones de hectáreas) en los últimos 25 años. Otra medida, es que se perdieron 4.3 millones de hectáreas en los últimos 10 años, o sea que la deforestación parece estar acelerándose. A nivel mundial, en 1990 los bosques cubrían el 31,6 por ciento de las zonas terrestres del planeta y en 2015 esa extensión pasó al

\footnotetext{
${ }^{5}$ Fuente no científica sino pronósticos de "visionarios"

${ }^{6}$ Carta del Cacique Seattle al Presidente de EEUU Franklin Pierce 1855

${ }^{7}$ Platón: “Diálogos” Ed. Porrúa México 1978
} 
30,6 por ciento. O sea que en 25 años se perdió 1,6\% de los bosques, cerca de 130 millones de hectáreas. ${ }^{8}$

La selva amazónica, el pulmón del mundo, está disminuyéndose alarmantemente.

Anualmente se destruyen 17 millones de hectáreas de bosques tropicales. Entre 1968 a 1996 el Amazonas disminuyó por 600.000 km2. ${ }^{9}$

Según Rolando Mendoza, Costa Rica deforesta por año 60.000 hectáreas de selva. ${ }^{10}$ Aunque aparentemente Costa Rica hoy corre otra suerte - no tanto por el hecho de que los "ticos" sean más ecológicos, sino porque aprecian la naturaleza como fuente de mayor ingreso-.

Según el profesor Arnoldo Mora, ex-ministro de Costa Rica, en la tierra desaparecen $¡ 1500$ especies de flora y fauna por semana!- $¡$ Son 84.000 por año! - ¡840.000 en 10 años! Él mismo expresa "Muchos biólogos están convencidos de que asistimos a una de las grandes extinciones de la historia del planeta. ¿Será posible evitarla?"

Pero resulta muy difícil evaluar la cantidad de especies que existen. "Solamente $10 \%$ de todas las especies han sido bautizadas con un nombre científico. Pero sabemos que el hombre las está destruyendo a un ritmo desenfrenado ${ }^{11}$. El pronóstico que nos dio Arnoldo Mora en una conferencia el día 2 de junio 2005 era bastante desolador: "La humanidad camina inexorablemente al suicidio."

Según una nota del diario "La Nación" / Costa Rica del 14/06/05 "los bosques tropicales se reducirán anualmente en un 1,6\% en Centroamérica y un 0,5\% en Suramérica hasta 2010, según previsiones de la FAO, los países de América del Sur perderán 36 millones de hectáreas y los de América Central 2,4 millones."

\section{Los Bosques preceden a los pueblos, los desiertos los siguen ${ }^{12}$.}

"(El hombre blanco) trata a la tierra, su madre, y a su hermano el cielo, como si fuesen cosas que se pueden comprar, saquear y vender, como si fuesen corderos y cuentas de vidrio. Su insaciable apetito devorará la tierra y dejará tras sí solo un desierto. ${ }^{13}$

Trabajar por la PAZ y la ECOLOGÍA es una cuestión de supervivencia, opinaba Arnoldo Mora. Cuando discutí este problema con los estudiantes de la facultad forestal de Misiones, me contestaron que la Naturaleza se regenera por sí sola. Recién cuando les preguntaba, si podrían engendrar hijos siendo castrados, aparentemente entendieron, pues

\footnotetext{
${ }^{8}$ Datos aportados por el Ingeniero Roberto L. Estévez

${ }^{9}$ Boff, L. Ecología, grito de la tierra. Ed Trotta 1996. Pag 114

${ }^{10}$ Mendoza, Rolando "Conservación ambiental y desarrollo sostenido". San Pedro, Costa Rica Los datos fueron recogidos por los años 80

11 E.O. Wilson UNESCO Mayo 2005

${ }^{12}$ René de Chateaubriand, escritor francés (1768 - 1848)

${ }^{13}$ O.c. Carta del Cacique Seattle
} 
¿Cómo la selva se puede regenerar por su cuenta, si los árboles semilleros fueron talados?

Llegué a la siguiente conclusión:

Si la mano del hombre destruye la naturaleza, ella necesita otra mano para regenerarla. La naturaleza necesita la ayuda, especialmente de las mujeres, para revertir el proceso destructor del hombre guerrero y cazador.

Volví a mi tierra verde y ya no estaba, ya no estaba, la tierra se había ido. Con el agua hacia el mar se había marchado. ${ }^{14}$

El triste descubrimiento de Neruda en Chile, se puede detectar en la mayoría de los arroyos y ríos de Latinoamérica, pues el color rojizo-marrón y el aumento del caudal de agua después de las lluvias, podrían convencer hasta al más tonto, cual es efecto de la deforestación irracional. Pero las respuestas a tal problema son siempre los mismos: "iNo me incumbe!"; “ ¿Para qué existe el ministerio de ecología?”;" ¡Siempre fue así!”; " ¡La tierra que el agua se lleva de Misiones, se deposita en el delta del Río de la Plata y de este modo vamos a tener más islas en el delta!"(Sic)

\section{La naturaleza no es nuestra, sino prestada de generaciones futuras.}

Otro peligro a nivel mundial está al acecho, aunque hasta ahora únicamente advertido por algunos científicos ecologistas. En una entrevista la meteoróloga Sol Osman dice:" miramos el océano y comprobamos que está siendo más ácido y que los arrecifes de coral se han destruido masivamente."

Por casualidad obtuve un resultado similar y nefasto: sembré y regalé semillas de lechuga a algunas personas. Las ensaladas eran muy ricas, excepto una. Ni era comestible a causa del mal gusto. Comprobé que la tierra era ácida.

Me hice recordar una maldición del profeta Jeremías:

Por eso, así dice Yavé de los ejércitos, Dios de Israel: "Yo daré de comer ajenjo a este pueblo y les voy a dar de beber agua envenenada. 9,14

Les daré como comida ajenjo, y como bebida agua envenenada, 23,15

O bien, Yo envenenaré la comida y el agua con ajenjo, pues es una planta venenosa! (Traducción propia libre para dar sentido al texto)

“Tocó el tercer ángel su trompeta, y una estrella grande, que parecía un globo de fuego, cayó del cielo sobre la tercera parte de los ríos y de los manantiales de agua. ${ }^{11}$ La estrella se llama Ajenjo: la tercera parte de las aguas se convirtió en ajenjo, y mucha gente murió a causa de las aguas que se habian vuelto amargas. Apoc.8, 11

${ }^{14}$ Pablo Neruda Oda a la erosión en la provincia de Malleco (1956) en Nuevas Odas elementales 


\section{Conclusión}

“iMire (Jesús) las estrellas! Son las mismas que veo en Nicaragua. Pero, si son las mismas estrellas, entonces es la misma tierra aquí y allá del rió San Juan. Entonces ¿Quién trazó las fronteras?" (Diálogo entre el Nica y Jesús en la obra "El Nica" de César Meléndez)

Dios es el Creador de toda la humanidad. Las naciones y fronteras son invento del ser humano. El sol sale para todos, o - citando a Jesús - "El sol brilla sobre buenos y malos." Dios nos dejó el planeta tierra a nuestra disposición: Acá lo tienen. Hagan que quieran, un paraíso o un infierno. Depende de Uds. cómo usan su libertad.

Hoy tenemos que admitir, que hemos fracasado como seres humanos, encargados de "cuidar y labrar el jardín". Nunca en la historia humana, el hombre destruyó tanto como a partir de la era de la industrialización. La contaminación del agua, aire y tierra ya parece irreversible. Además en la manera que el ser humano se alejó de la dependencia arbitraria de la naturaleza, entró en una dependencia arbitraria del hombre: "homo lupus hominis", como admitieron los fundadores el sistema capitalista.

La tentación del hombre/mujer es querer ser igual a Dios (Gen. 3 y 8), de no aceptar ser creatura sino creerse creador, nos hace caer en la trampa de la autodestrucción. Ya no hace falta un "fin del mundo" por parte de Dios, ni la bomba atómica, sino nosotros mismos lo estamos haciendo poco a poco, despacito, despacito.

Lo poco que aprendí durante mi vida respeto a la relación del ser humano con Dios, los hombres y la naturaleza, lo logré expresar en una frase: Dios perdona siempre. El hombre de vez en cuando, la Naturaleza nunca.

Todos los crímenes que comete el hombre (más que la mujer) contra la naturaleza, volverá como efecto boomerang hacia él mismo. Creo que la única salida de la humanidad para salir de este callejón sin salida, sería humildemente pedir perdón a las futuras generaciones, a la naturaleza, y a Dios, admitiendo que nos comportamos como el "aprendiz de brujo" de J.W. Goethe, cual fue incapaz de deshacerse de los espíritus que él había llamado.

Y, ¡manos a la obra en la reconstrucción de un mundo mejor; en una "civilización de amor"! como pregonaba Pablo VI.

\section{6. ¿Las tinieblas no desaparecen lamentándolas, si no enciendo una luz!}

Por suerte, ante el peligro de la autodestrucción de la humanidad, se levantan muchas voces y movimientos en defensa de la Naturaleza, como Greenpeace, Vida Silvestre, Wild World Foundation, Justicia, Paz y Ecología, Foro Emaús, COPROLADE,etc 
¿Podemos hacer algo, para salvar la naturaleza?, para dejar el mundo más habitable para las futuras generaciones? - ¿Qué podemos hacer?

1. Cambiar la mentalidad. Salir del letargo en que los pueblos parecen estar sumergidos. Abogar a favor de la VIDA en una sociedad "a favor de la muerte."

2. Que los cristianos se acuerden de su sentido aquí en la tierra: ser instrumento de Dios para que su Reino crezca y que dejen de lado las discusiones estériles doctrinales, que nos separan más que unirnos.

3. Adherirnos a los grupos ecológicos existentes.

4. Educar a los chicos de buscar vivir en armonía con la naturaleza.

5. La ecología empieza en casa. Usar los recursos no renovables a manera responsable. Buscar energía alternativa por ej. calefacción solar de agua o biogás para casas del campo.

Reciclar la "basura”. ¡Lo orgánico vuelve a ser tierra!

6. Juntar el agua pluvial en depósitos para uso casero.

7. Que empecemos a reforestar donde podemos. Cada árbol que plantamos ya es un logro. Hasta ahora únicamente la reforestación a nivel global podría fijar parte de $\mathrm{CO}_{2}$ y de esta manera amortiguar los efectos negativos que amenaza a la humanidad entera.

8. Hacer campañas en contra de la deforestación y a favor de la reforestación.

9. Que cada municipalidad y provincia reserve una parte se su terreno como "Reserva ecológica". Por lo menos para que las futuras generaciones sepan cómo era el ambiente antes. O sea, “iqué criminales eran nuestros antepasados!".

10. Repoblar el campo. Favorecer la diversidad de culturas. Elaborar un ecosistema en que el hombre puede participar activamente para que las comunidades pueden - en lo posible- autoabastecerse.

En Latinoamérica desde el implante del sistema neoliberal, la relación demográfico del campo-ciudad se convirtió a $180^{\circ}$. Antes era $70 \%$ campo y $30 \%$ ciudad. En Argentina viven actualmente 93,5\% en y alrededor de las grandes ciudades.

El éxodo de la gente de la city al campo se está realizando en Francia.

11. Reemplazar los agro-tóxicos por otros métodos no-mortales para el ambiente.

¡Estaría agradecido por más sugerencias! 


\section{Bibliografía}

Rolando Mendoza: “Conservación ambiental y desarrollo sostenido." San Pedro, C.Rica

Platón: “Diálogos" Ed. Porrúa México 1978

Documentos en torno a la Biblia 6: la creación del mundo y del hombre Ed.

Verbo Divino / Estella 1982

A. Recinos: Popol Vuh / Ed. Fondo de cultura económica / Bs. As. 1961

S. Croatto: crear y amar en libertad/Ed. Aurora / Bs. As. 1986

Koch: Der Baumtest

J.Gafo:10 palabras clave Ecología / Ed. Verbo Divino/ Estella.1998

Ingemar Hedstrôm: ¿Volveràn las golondrinas? Ed. DEI 1990

S. Croatto: libertad y liberación / Ed.Aurora 1988

L. Boff: Ecología, grito de la tierra Ed. Trotta, 1996

Datos aportados por Ing. Roberto L. Estévez. Mapa interactivo de los bosques mundiales http://www.globalforestwatch.org/ map/4/-40.43/-63.62 / ARG/grayscale/ loss,forestgain?tab=analysis-tab\&begin=2001-01-01\&end=2014-12-30\&threshold=30 (consultado $07 / 03 / 2019$ )

Muestra en rosado los bosques perdidos y en azul los plantados también están las imágenes, para copiar y pegar http://blog.globalforestwatch.org / data /9-maps-that-explain-the-worlds-forests.html

René de Chateaubriand, escritor francés (1768 - 1848)

Proverbios: Sabiduría del pueblo de Israel / 2.ed. p.14 Ed.San José, Posadas 2002

\section{Biografía consultada:}

S. Croatto: el hombre en el mundo 1/Ed. Aurora Bs. As. 1974 Ian Bradley: Dios es verde /Ed. Sal Térrea, Santander, 93

Giacomo Panteghini: El gemido de la creación / Ed San Pablo, 94

Leonardo Boff; La Ética de la Madre Tierra/ Ed Santa María, Bs. As. 2016 Papa Francisco: Encíclica "Laudato Si"

Wolfram Dressler Moellenbruck svd wolfran74@gmail.com 